\title{
Soil factors affecting the germination of potatoes left on the field after harvest
}

\author{
F. R. Boone and C. J. van der Elst \\ Tillage Laboratory, Agricultural University, Diedenweg 20, Wageningen, the \\ Netherlands
}

Accepted: 25 January 1977

Key words: Volunteer potatoes, groundkeepers, soil structure, mechanical crushing, germination

\section{Summary}

In the humid and mild winters in the Netherlands $80 \%$ of all tubers left on the field after harvest decay after ploughing. In the laboratory and in a model experiment in a soil bin the following aspects were investigated: rate of rotting under favourable conditions for rotting, characterization of loss of germinability and subsequent rotting and the effect of soil structure, depth of placement and crushing of the tubers on rotting.

The results during the extremely wet autumn and winter 1974-1975 indicate that there is a wide range of soil structures that have no effect on rotting. To get rid of all tubers soil structure has to be very unfavourable. Burying the tubers more deeply was only slightly favourable.

Although crushing is favourable in principle, its success depends on several factors that need further research. Maximizing the chances of rotting and freezing simultaneously seems to be most promising.

\section{Introduction}

Potatoes left on the field after harvest are a serious problem, because even very small tubers can produce volunteer plants the next year. Volunteer plants are a troublesome weed especially because they maintain or even increase the population of the nematode Heterodera rostochiensis.

The number of potatoes left on the field is very variable. Fortunately most of them lose their germinability in autumn or winter. From many observations in the Netherlands (Lumkes, 1974b) we can calculate that, when ploughing is the main tillage operation, on average only $20 \%$ of the tubers left on the field actually give a volunteer plant. However the differences between different fields and years are large. This variability cannot be explained only by differences in numbers of tubers killed by freezing. 
Tillage research in recent years has been concentrated on increasing the chances of freezing tubers, the objective being to combine an adequate soil structure with a placement of the tubers as near to the surface as possible. On average the number of volunteer potatoes is reduced by using a modified cultivator with fixed tines instead of a mouldboard plough (Lumkes, 1974a). However, in years when the frost only penetrates the soil superficially, as quite often happens in the Netherlands, many tubers remain alive.

Until recently hardly any attention has been paid to the factors that affect rotting of tubers in the arable layer during autumn and winter. This article deals with observations from model research on how soil structure, depth of placement and mechanical crushing can affect rotting of small potato tubers.

\section{Material and methods}

For the experiments from November 1974 to June 1975, unless stated otherwise, potato tubers (cv. Bintje) with a diameter of $25 \mathrm{~mm}$ and a germinability of $92 \%$, left on the field after harvest, were used.

\section{Characterization and rate of rotting}

To obtain material for the experiments, all conducted in the laboratory at $20^{\circ} \mathrm{C}$, and to get an idea about the rate of rotting under extreme conditions, tubers were submerged in tapwater.

The rate of rotting under very humid soil conditions was determined by placing tubers in a loose soil (loam, $15 \%<2 \mu \mathrm{m})$ at different heights above a watertable. Some of the tubers were cut in two and placed in the soil immediately. After one and four weeks the numbers of germinated and clearly rotten tubers were counted.

The oxygen consumption of healthy and rotten tubers were calculated from measurements of the oxygen concentration (polarographic method) in small closed jars with four tubers. Some of the healthy tubers were submerged in tapwater. In addition changes in weight of undamaged and lightly damaged tubers placed in a thin layer of water were determined.

The resistance of tubers to compression was measured in a linear speed compression machine (speed $0.17 \mathrm{~mm} \mathrm{~s}^{-1}$ ), and the same machine was used to measure the cone resistance (cone diameter $2 \mathrm{~mm}$ ).

\section{Soil structure, depth of placement in the soil and crushing of the tubers in relation} to rotting

Soil structure, especially soil structure heterogeneity (Boone, 1976) and distribution of tubers in the arable layer, are clearly altered by tillage. After mouldboard ploughing or cultivating with a fixed tine cultivator, part of the tubers are surrounded by loose soil, and others by more dense soil. After the main tillage operation part of the soil is compacted again by other field operations. Because soil density and depth of placement in the soil affect tuber aeration - and therefore perhaps germinability 
and rotting - both factors were studies for undamaged and mechanically crushed tubers.

Tubers were placed at several depths in a soil bin, containing $80 \mathrm{~cm}$ of a loam $(15 \%<2 \mu \mathrm{m})$ above an undisturbed sandy subsoil with a very deep water-table. At the same moment the loose soil, which was at field capacity, was compacted layer by layer very lightly and very heavily, respectively. In a few instances tubers with a diameter of $15 \mathrm{~mm}$ as well as tubers with a diameter of $25 \mathrm{~mm}$ were used.

Harvesting losses (cv. Bintje, germinability $92 \%$ ) from another field and stored in a cold store were crushed (Meijer, 1975). Whole crushed tubers as well as pieces were placed in the soil bin one day after being crushed. Two or three pieces were placed together and counted as one tuber.

The temperature above and at different depths in the soil was measured continuously, the oxygen concentration of the soil air periodically.

After 6 and 12 weeks undisturbed cores of $100 \mathrm{~cm}^{3}$ were sampled for standard soil physical determinations and part of the tubers were dug out. The numbers of germinated and clearly rotten tubers were counted and the germinability of the tubers was determined at $20^{\circ} \mathrm{C}$ after 2 and 4 weeks in the laboratory. A part of the material was used for the compression test.

In spring the date of emergence of the potato plants was recorded. Six months after the start of the experiment (early June 1975), the number of germinated tubers and the number and length of the sprouts were determined.

\section{Results}

\section{Characterization and rate of rotting}

Tubers submerged in water started rotting in the laboratory at $20^{\circ} \mathrm{C}$ quite quickly: some tubers started within one week, most tubers within 2 or 3 weeks after submergence. Tubers damaged at harvesting were more susceptible to rotting than undamaged tubers. In contrast to healthy tubers, which absorbed some water, the weight of the rotten tuber decreased by about $20 \%$ in two weeks. The tuber content

Table 1. Germination and rotting after four weeks of whole tubers and tubers cut in two in a loose soil at different heigths above a watertable $(n=25)$.

\begin{tabular}{lll}
\hline $\begin{array}{l}\text { Height above } \\
\text { water-table }(\mathrm{cm})\end{array}$ & Rotting (\%) & Germination (\%) \\
25 & 53 & 13 \\
$25^{*}$ & 80 & 10 \\
20 & 60 & 10 \\
15 & 70 & 0 \\
10 & 68 & 0 \\
5 & 84 & 0 \\
\hline
\end{tabular}

* Half tubers. 


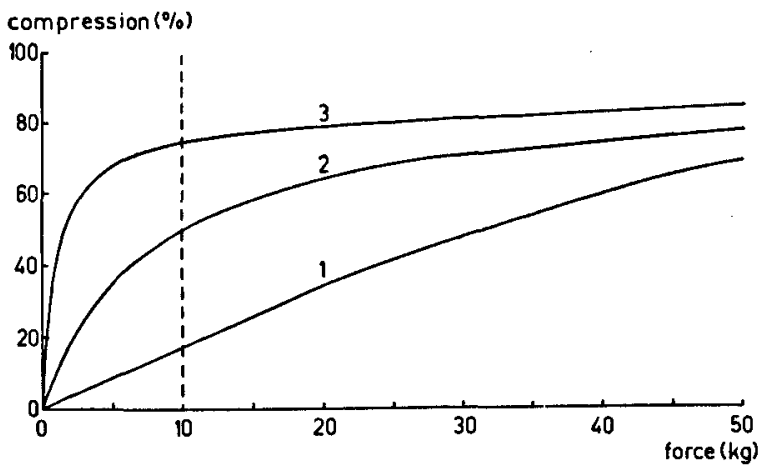

Fig. 1. Relation between applied force and the compression of an undamaged (1), partly rotten (2) and completely rotten tuber (3) (Ø $25 \mathrm{~mm}$ ).

softened slowly and decayed. Many tubers floated in water, because the gases formed passed slowly through the skin which remained intact the longest.

The wetter the soil the faster the tubers started to rot (Table 1). Tubers that were placed in the soil immediately after cutting were more susceptible than whole tubers. Already after one week some half tubers were rotten.

Healthy tubers consumed about $1 \mu \mathrm{g} \mathrm{O}_{2} \mathrm{~kg}^{-1} \mathrm{~s}^{-1}$. Oxygen consumption at the start of rotting increased very sharply to $5-15 \mu \mathrm{g} \mathrm{O}_{2} \mathrm{~kg}^{-1} \mathrm{~s}^{-1}$. Oxygen consumption of germinating tubers was intermediate.

Because rotting was accompanied by a softening of the tubers we tried to quantify this latter process. Cone resistance varied markedly from one place to another. This result is in agreement with the observation that start and rate of rotting differed for different parts of the tuber. The compression in the compression machine, on the other hand, gives an overall impression of softening (Fig. 1). The compression as a percentage of the original diameter at a force of $10 \mathrm{~kg}$ was chosen as characteristic.

Soil structure, depth of placement in the soil and crushing of the tubers in relation to rotting

The soil environment. At the same depth in the soil bin the pore volume in the loose soil was about $5 \%$ higher than in the dense soil (Table 2). Especially in the loose

Table 2. Pore volume and air content at pF 2.0 of the loose and dense soil in the soil bin $(n \geqslant 10)$.

\begin{tabular}{|c|c|c|c|c|}
\hline \multirow[t]{2}{*}{ Depth $(\mathrm{cm})$} & \multicolumn{2}{|c|}{ Loose soil } & \multicolumn{2}{|c|}{ Dense soil } \\
\hline & $\begin{array}{l}\text { pore } \\
\text { volume } \\
\text { (\%) }\end{array}$ & $\begin{array}{l}\text { air content } \\
\text { at pF } 2.0(\%)\end{array}$ & $\begin{array}{l}\text { pore } \\
\text { volume } \\
\text { (\%) }\end{array}$ & $\begin{array}{l}\text { air content } \\
\text { at } \mathrm{pF} 2.0(\%)\end{array}$ \\
\hline $2-7$ & 47.6 & 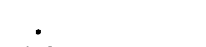 & & . \\
\hline $7-12$ & 48.2 & 18.0 & 42.8 & 11.3 \\
\hline $22-27$ & 45.6 & 16.0 & 41.0 & 11.9 \\
\hline $47-52$ & 43.0 & . & . & . \\
\hline
\end{tabular}


Table 3. Rainfall and mean temperature just above and in the soil bin.

\begin{tabular}{lllll}
\hline Period & $\begin{array}{l}\text { Rainfall } \\
(\mathrm{mm})\end{array}$ & \multicolumn{3}{l}{ Mean temperature $\left({ }^{\circ} \mathrm{C}\right)$ at } \\
\cline { 3 - 6 } \cline { 3 - 6 } & & $\begin{array}{l}0 \mathrm{~cm} \\
\text { depth }\end{array}$ & $\begin{array}{l}10 \mathrm{~cm} \\
\text { depth }\end{array}$ & $\begin{array}{l}25 \mathrm{~cm} \\
\text { depth }\end{array}$ \\
December 1974, 2nd half & 61.2 & 6.1 & 6.2 & 6.2 \\
January 1975, 1st half & 28.1 & 5.2 & 4.9 & 5.5 \\
January 1975, 2nd half & 56.4 & 4.3 & 4.4 & 4.9 \\
February 1975, 1st half & 20.1 & 3.0 & 3.1 & 3.9 \\
February 1975, 2nd half & 8.4 & 3.4 & 2.5 & 2.9 \\
March 1975, 1st half & 28.9 & 7.0 & 5.8 & 5.6 \\
March 1975, 2nd half & 48.3 & 4.5 & 3.7 & 4.1 \\
\hline
\end{tabular}

soil pore volume decreased with depth: at a depth of $50 \mathrm{~cm}$ pore volume was even quite low. This observation coincides with periods of very wet weather during the experiment (Table 3). At compaction the soil was relatively wet, so it can be assumed that on the dense soil also some soil puddling was the resuit. In fact pools formed on the dense soil for several hours after heavy rains.

In periods with a high rainfall soil water content was somewhat higher than at pF 2.0. The mean oxygen concentration of the soil air in the loose soil, however, never decreased below $20 \%$, not even at a depth of $50 \mathrm{~cm}$ (Table 4). The air content of the dense soil, that was still about $11 \%$ at $\mathrm{pF} 2.0$, temporarily decreased below $6 \%$. As a result the mean oxygen concentration decreased sharply, although differences were large between the separate measurements. This variability is also illustrated by the number of small diffusion chambers $\left(1 \mathrm{~cm}^{3}\right)$ temporarily clogged. Nevertheless, in relatively dry periods the oxygen concentration increased markedly to a somewhat lower level than in the loose soil.

Observations on potato tubers. Six weeks after the start of the experiment striking differences in rotting were found (Table 5). Nearly all uncrushed tubers in the dense soil had lost their ability to germinate. In contrast in the loose soil about half could still germinate. For tubers placed on top of the soil germinability was even higher, whereas crushing also had a clearly negative effect. This negative effect appeared also in the dense soil.

Table 4. Oxygen concentration (\%) of the soil air at different dates and depths in the soil bin. Between brackets is given the number of clogged gas diffusion chambers $(n=10)$.

\begin{tabular}{|c|c|c|c|c|c|c|c|c|}
\hline \multirow[t]{2}{*}{ Depth $(\mathrm{cm})$} & \multicolumn{4}{|c|}{ Loose soil } & \multicolumn{4}{|c|}{ Dense soil } \\
\hline & $8 / 1$ & $24 / 1$ & $11 / 2$ & $13 / 3$ & $8 / 1$ & $24 / 1$ & $11 / 2$ & $13 / 3$ \\
\hline 10 & 20.7 & 20.8 & 21.0 & 21.0 & $15.4(3)$ & $16.2(2)$ & 20.7 & 20.8 \\
\hline 25 & 20.1 & 20.5 & 20.7 & 20.7 & $7.6(7)$ & $4.8(6)$ & 14.6 & $12.6(3)$ \\
\hline 50 & 20.0 & 20.5 & 20.3 & 20.6 & & & & \\
\hline
\end{tabular}


Table 5. Germination in the soil bin and germinability of the tubers 6 weeks, 12 weeks and 6 months after the start of the experiment (mean of tubers at 10 and $25 \mathrm{~cm}$ depth).

\begin{tabular}{|c|c|c|c|c|}
\hline & \multicolumn{2}{|c|}{ Germination $(\%)$} & \multicolumn{2}{|c|}{ Germinability (\%) } \\
\hline & uncrushed & crushed & uncrushed & crushed \\
\hline \multicolumn{5}{|l|}{ Loose soil } \\
\hline After 6 weeks & 33 & 42 & 48 & 74 \\
\hline After 12 weeks & 33 & 81 & 48 & 89 \\
\hline After 6 months & 39 & 94 & 39 & 94 \\
\hline \multicolumn{5}{|l|}{ Dense soil } \\
\hline After 6 weeks & $\mathbf{0}$ & 3 & 3 & 11 \\
\hline After 12 weeks & 0 & 4 & 0 & 10 \\
\hline After 6 months & 0 & 6 & 0 & 6 \\
\hline
\end{tabular}

Between the sixth and twelfth week there was some frost causing loss of germinability of all tubers placed on top of the soil. At a depth of $5 \mathrm{~cm}$ no frost at all was recorded.

In spite of several rainy periods and wet soil conditions, the germinability of uncrushed tubers in loose soil decreased only slowly after six weeks. The crushed tubers even maintained a high germinability.

There is a negative linear relation between compressibility and germinability. This relation is not unique, however, because it also depends on age, diameter and crushing of the tubers (Fig. 2).

The mild winter promoted germination: at six weeks quite a lot of tubers had already germinated. Especially the second observation showed that crushing promoted germination.

The deeper the tubers were placed the later the sprouts emerged (Table 6). Tubers

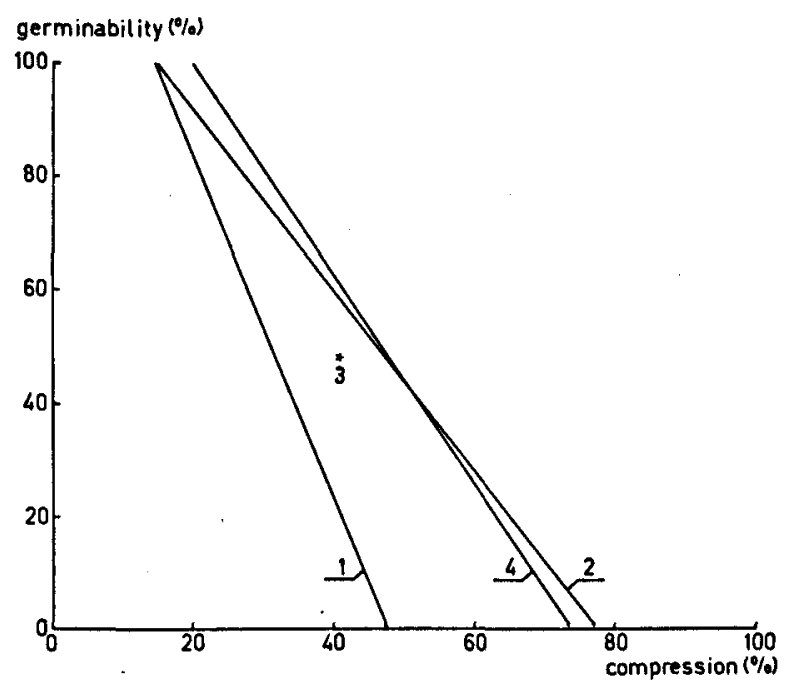

Fig. 2. Relation between the compression and germinability of: (1) uncrushed tubers after 6 weeks $(\varnothing 25 \mathrm{~mm})$; (2) crushed tubers after 6 weeks (Ø $25 \mathrm{~mm}$ ); (3) uncrushed tubers after 6 weeks (Ø $15 \mathrm{~mm}$ ); (4) uncrushed tubers after 12 weeks (Ø $25 \mathrm{~mm})$. 
Table 6. Date at which the first volunteer plants emerged in the soil bin.

\begin{tabular}{|c|c|c|c|}
\hline \multirow[t]{2}{*}{ Depth $(\mathrm{cm})$} & \multicolumn{2}{|l|}{ Loose soil } & \multirow{2}{*}{$\begin{array}{l}\text { Dense soil } \\
\text { crushed }\end{array}$} \\
\hline & uncrushed & crushed & \\
\hline 5 & $20 / 4$ & . & . \\
\hline 10 & $20 / 4$ & $24 / 4$ & $12 / 5$ \\
\hline 25 & $20 / 5$ & $18 / 5$ & . \\
\hline 50 & after $10 / 6$ & . & . \\
\hline
\end{tabular}

from a depth of $5 \mathrm{~cm}$ emerged several weeks earlier than tubers from a depth of $25 \mathrm{~cm}$. The effect of crushing is not clear in this respect, but a dense soil strongly impedes the growth of the sprouts in the soil.

Between tubers from 10 and $25 \mathrm{~cm}$ there were no significant differences in germinability either at 6 or 12 weeks. The results at smaller or greater depths showed a higher variability, but on average they were somewhat lower. This variability partly can be explained by accidental differences in soil structure. At the end of the experiment in June 1975 there was a gradual but small decrease in ultimate germination with depth (Table 7).

At that time also the total number of sprouts of the uncrushed tubers decreased slightly with depth (Fig. 3). The number of sprouts above the soil decreased, however, sharply with depth. As late as early June no sprout had emerged from a depth of $50 \mathrm{~cm}$. As a consequence the number of sprouts that had not yet emerged increased sharply with depth. Only about $1 / 3$ of them were longer than half the distance between the tuber and the soil surface.

Chrushing resulted in a higher number of sprouts per germinated tuber, especially when the tubers were not buried deeply (Table 8).

At the start of the experiment tubers with a diameter of 25 as well as tubers with a diameter of $15 \mathrm{~mm}$ had a germinability of $92 \%$. After 6 and 12 weeks and 6 months germinability of the smaller tubers was $3-5 \%$ lower.

\section{Discussion}

Not all healthy-looking tubers were able to germinate. Because loss of germinability and rotting is accompanied by tuber softening, a compressibility test perhaps

Table 7. Tuber germination (\%) in the soil bin at the end of the experiment (June 1975).

\begin{tabular}{llllll}
\hline Depth $(\mathrm{cm})$ & \multicolumn{2}{l}{ Loose soil } & & \multicolumn{2}{l}{ Dense soil } \\
\cline { 2 - 3 } \cline { 5 - 6 } & uncrushed & crushed & & uncrushed & crushed \\
5 & 43 & & & & \\
10 & 40 & 100 & & 0 & 12 \\
25 & 38 & 88 & 0 & 0 \\
50 & 30 & & & &. \\
\hline
\end{tabular}




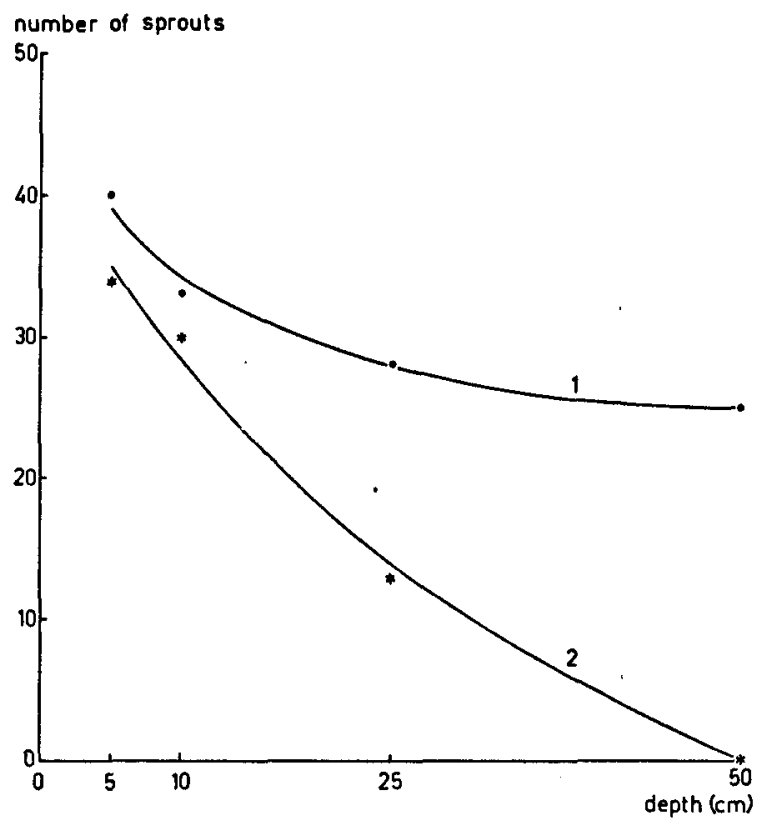

Fig. 3. Relation between total number of sprouts (1), number of sprouts above the soil (2) and depth of placement in a loose soil at the end of the experiment (uncrushed tubers; June 1975).

could replace the determination of germinability. However, there is no unique relation between these factors because size, age and crushing of the tubers modified the results.

Even though autumn and winter of $1974 / 1975$ were very wet, about one third of the tubers in a very well drained loose soil did not lose their ability to germinate. According to the test used, most tubers lost their germinability within 6 weeks after the start of the experiment. This result agrees with the observation in the laboratory that, when circumstances are favourable for rotting, the most susceptible tubers start rotting quite fast. More resistent tubers lose germinability only in a more extreme environment. The fact that $30 \%$ of the tubers at a depth of $50 \mathrm{~cm}$ with an unfavourable soil structure were germinated at the end of the experiment, indicates that the most resistent tubers only die in an extreme environment.

A heavily compacted soil or a soil with a bad drainage are examples of such an

Table 8. Number of sprouts per germinated tuber in loose soil in the soil bin at the end of the experiment (June 1975).

\begin{tabular}{lll}
\hline Depth (cm) & Uncrushed & Crushed \\
5 & 1.48 & \\
10 & 1.32 & 3.31 \\
25 & 1.16 & 1.64 \\
50 & 1.31 & $\cdot$ \\
\hline
\end{tabular}


extreme environment. A nearly water-impermeable layer on the surface, a severe plough pan or a strongly fluctuating water-table enhance tuber rotting but are otherwise situations that should be avoided. With a reasonable soil structure and good drainage, the experimental results do not indicate that the problem is solved just by burying the tubers more deeply. However deeper tubers emerge (much) later and produce weaker plants initially, which can be important from the competition point of view.

At $20^{\circ} \mathrm{C}$ an extremely high number of 100 healthy tubers $\mathrm{m}^{-2}\left(10^{6} \mathrm{ha}^{-1}\right)$ consume $1 \mu \mathrm{g} \mathrm{O}_{2} \mathrm{~m}^{-2} \mathrm{~s}^{-1}$, the same number of rotten tubers $10 \mu \mathrm{g} \mathrm{O}_{2} \mathrm{~m}^{-2} \mathrm{~s}^{-1}$. The soil mass itself consumes during the growing season at least $30 \mu \mathrm{g} \mathrm{O}_{2} \mathrm{~m}^{-2} \mathrm{~s}^{-1}$ (Brown, 1965), so we can conclude that the oxygen consumption of potato harvesting losses is only a small part of the total oxygen consumption. As respiration decreases by a factor 2 to 3 every $10^{\circ} \mathrm{C}$, oxygen consumption during winter is much lower than during the growing season. So a low oxygen concentration can only be expected when the soil has a very low gas diffusion coefficient. In the loose soil no low oxygen concentrations were found, and on the very poor soil structure only during very wet periods.

Nevertheless, the soil environment just around the tubers is much more important than the mean soil structure, because the oxygen consumption of a tuber is much higher than the same volume of soil. Soil structure variability and distribution of tubers in the arable layer are both clearly influenced by tillage. A clustered distribution of tubers in combination with very fine soil material around the tubers is a different situation from a normal tuber distribution in a well aggregated soil. Extrapolation of results from a homogenous to a heterogeneous situation should be done very carefully.

Tubers cut in two and buried in a wet soil immediately rot faster than whole tubers. While the wound is not yet suberized micro-organisms can easily infect it. A high humidity of the air around the tuber and a relatively high temperature are favourable for this suberization (Reestman, 1960).

Factors such as soil temperature, soil water content at crushing, the degree of crushing, time between crushing and the main tillage operation, tillage applied and weather conditions after crushing, all influence the results. When the combination of factors is unfavourable, as in the model experiment in the soil bin, crushing can even have a negative effect. The first promising experiments in practice (Meijer, 1975) show that crushing halved the number of volunteer plants. To improve these results, more research is needed to analyse the different factors that influence rotting. Probably most promising is to maximize both the chances for rotting as well as for freezing of the tubers.

\section{Conclusions}

When conditions for rotting were very favourable, tubers started rotting within one week. Although loss of germinability and subsequent rotting is accompanied by a higher mechanical compressibility of the tubers, there was no unique relation between these factors. 
It is possible to change soil structure in such a way that all tubers decay quite fast. However, the results during the very wet autumn and winter of 1974/1975 indicate that there is a large range of soil structures that have no influence on rotting. Soil structure must be extremely unfavourable to get rid of all tubers. The soil environment around the tuber is much more important than the soil structure at greater distances. When there is no interaction with other interfering factors such as insufficient drainage, burying of the tubers more deeply is only slightly favourable.

Although crushing the tubers is favourable in principle, its success depends on several factors that need further research. Maximizing the chances of rotting and freezing simultaneously seems to be most promising.

\section{References}

Boone, F. R., 1976. Notes on soil structure homogeneity and rootability. Proc. 7th Conf. Int. Soil Tillage Res. Orgn (ISTRO) (Uppsala, Sweden, 1976), Rep. Div. Soil Mangmt Agric. Coll. Sweden 45.

Brown, N. J., E. R. Fountaine \& M. R. Holden, 1965. The oxygen requirement of crop roots and soils under near field conditions. J. agric. Sci. 64: 195-203.

Lumkes, L. M., 1974a. Analyse van de bestrijdingsmogelijkheden van opslagaardappelen. Landbouwk. Tijdschr. 86 (1): 6-13. (In Dutch.)

Lumkes, L. M., 1974b. Potatoes as a weed. Publ. Res. Stn Arable Farm. 15; 38 pp.

Meijer, E. N. C. \& J. Frederiks, 1975. The crushing of discards and potatoes which fall through the web to control groundkeepers. Abstr. Conf. Pap. 6th trienn. Conf. Eur. Ass. Potato Res. (Wageningen, Netherlands, 1975): 119-120.

Reestman, A. J., A. Schepers \& J. C. Mooi, 1960. Over het snijden van pootaardappelen. Publ. Proefstn Akker-en Weidebouw 9; 24 pp. 